\title{
APOSTADEROS DE PINNÍPEDOS EN PUNTA ENTRADA (SANTA CRUZ, PATAGONIA ARGENTINA). EXPLOTACIÓN HUMANA E HISTORIA NATURAL
}

ISABEL CRUZ*, SEBASTIÁN MUÑOZ*, BETTINA ERCOLANO*, CLARA R. LEMAIRE", ADRIANA PRETTO**, GUSTAVO NAUTO" \& CAROLINA MORENO***

\section{RESUMEN}

El análisis de dos conjuntos zooarqueológicos de Punta Entrada, en la desembocadura del río Santa Cruz (Patagonia Argentina), permite abordar el tema de la existencia y explotación de apostaderos de lobos marinos en la localidad. Las características de estos conjuntos incluyen el predominio de los restos de pinnípedos, la representación de dos especies (Otaria flavescens y Arctocephalus australis), la presencia de ambos sexos y de individuos de diversas edades, modificaciones antrópicas y una gran diversidad de partes esqueletarias representadas. Los restos de cachorros de 1-1,5 meses en uno de los depósitos permiten establecer que el apostadero era reproductivo. Los perfiles anatómicos indican el transporte de individuos enteros o casi enteros desde un lugar cercano, que pudo ubicarse sobre la costa atlántica inmediatamente al sur de la localidad, donde la playa y el acantilado son similares a los hábitats en que los pinnípedos emplazan actualmente sus asentamientos. Otro lugar posible es el sector este de Punta Entrada, cuya historia de formación permite suponer que presentaba las mismas características. Además, las fuentes históricas mencionan una isla en el estuario en la que habitualmente se avistaban lobos marinos. Si bien estos hábitats son los que utiliza $O$. flavescens, la presencia de restos de $A$. australis en Punta Entrada permite suponer que esta especie también los utilizaba, aunque actualmente prefiera otros. Durante los últimos 2.000 años, el aprovechamiento de estos apostaderos por las poblaciones humanas no habría sido ni continuo ni relacionado con una estación específica del año.

PALABRAS CLAVE: apostaderos de pinnípedos, cazadores-recolectores costeros, zooarqueología, Otaria flavescens, Arctocephalus australis

\section{PINNIPED ROCKERIES AT PUNTA ENTRADA (SANTA CRUZ, PATAGONIA ARGENTINA). HUMAN EXPLOITATION AND NATURAL HISTORY}

\footnotetext{
ABSTRACT

The analysis of two zooarchaeological assemblages from Santa Cruz river mouth -Punta Entrada(Patagonia Argentina) allows to postulate the past existence and human exploitation of sea lions breeding

* Unidad Académica Río Gallegos, Universidad Nacional de la Patagonia Austral. isabelzooarqueologia@gmail.com

* Laboratorio de Zooarqueología y Tafonomía de Zonas Áridas, IDACOR-CONICET/Universidad Nacional de Córdoba.

*** Laboratorio de Zooarqueología y Tafonomía de Zonas Áridas, IDACOR/Universidad Nacional de Córdoba

Parque Nacional Monte León, Administración de Parques Nacionales.
} 
rookeries in this locality. The assemblages show a dominance of pinniped bones, including two different species (Otaria flavescens y Arctocephalus australis), which correspond to individuals of both sexes and different ages; several body parts are represented and bones are cut marked. One and a half month of age puppy bones recovered in one deposit allow to postulate the rockery was a reproductive one. The anatomical part representation is interpreted as the result of transportation of complete, or nearly complete, individuals from a closer place, which could have been the Atlantic coast right south this locality. The costal cliffs and beach found there fits to present day habitats chosen by these pinnipeds to establish their colonies. Eastern Punta Entrada is another possible location, since its geomorphological history allows expecting conditions similar to those found in the Atlantic coast. Historical records mention the existence of an estuarine island inhabited by sea lions as well. Although the already mentioned habitats are those chosen by $O$. flavescens, the A. australis bones recovered in Punta Entrada suggest that these habitats could have also been chosen by this species in the past, in spite of chosing different settings at present. The human use of these rockeries took place during the last 2000 years but would have not been continuous nor based on a seasonal basis.

KEY WORDS: pinniped breeding rookeries, coastal hunter-gatherers, zooarchaeology, Otaria flavescens, Arctocephalus australis

\section{INTRODUCCIÓN}

La disponibilidad de pinnípedos y la forma en que los humanos los explotaban en el pasado son temas que aún se discuten en muchas regiones del mundo. En Patagonia el cuadro no es muy diferente y muestra que las relaciones entre ambos han sido variables a lo largo del Holoceno (ver Muñoz 2011, para una síntesis). Entre los factores que promovieron estas variaciones se destacan los cambios en la distribución y abundancia de los pinnípedos patagónicos a lo largo del tiempo debido a factores climáticos/ambientales o antrópicos. Por ejemplo, se ha planteado que, tal como sucedió con otras especies, la distribución de los pinnípedos fue afectada por la última glaciación, cuando ambas especies sufrieron contracciones demográficas durante el avance glaciario, seguidas de expansiones cuando se retrajeron (Túnez et al. 2010, 2013). Con respecto al impacto antrópico, son varios los autores que señalan que la matanza con fines comerciales que se inicia en el siglo XVIII es un punto de inflexión que diezmó las poblaciones de pinnípedos patagónicos casi hasta la extinción (Crespo y Pedraza 1991; Rodríguez y Bastida 1998; Orquera 2002; entre otros). En este marco, establecer la existencia pasada de apostaderos en sectores particulares de la costa es una vía de análisis importante para conocer la historia natural de estos animales y discutir su interacción con las poblaciones humanas. Los estudios zooarqueológicos son una herramienta adecuada para abordar este y otros aspectos vinculados con la distribución pasada de una especie, ya que permiten evaluar las variaciones a lo largo de lapsos prolongados e identificar las posibles causas de las mismas (Frazier 2007; Lyman 2012; Lyman y Cannon 2004; entre otros).

Aquí nos centraremos en evaluar la existencia de apostaderos de pinnípedos en Punta Entrada, un sector de la costa atlántica de Patagonia continental que actualmente carece de ellos, para discutir su explotación por las poblaciones humanas durante el Holoceno Tardío. Para esto, se presenta el análisis zooarqueológico de P 96 y P 37, dos depósitos arqueológicos de la localidad. En líneas generales, Punta Entrada se caracteriza por la presencia de depósitos a cielo abierto con abundantes restos óseos y líticos, con fechados que no exceden los 2.100 años AP (Muñoz et al. 2009) y evidencia de una intensa explotación de pinnípedos. En relación con el objetivo del trabajo, se presentan los resultados zooarqueológicos en función de las variables que consideramos relevantes para evaluar la existencia y explotación de apostaderos de pinnípedos. Además, se discute brevemente el potencial de las fuentes históricas para abordar el tema y, luego, se integran estos resultados con la información biológica actual y la historia de formación de Punta Entrada para proponer cuales habrían sido en el pasado los sectores más apropiados para el emplazamiento de 


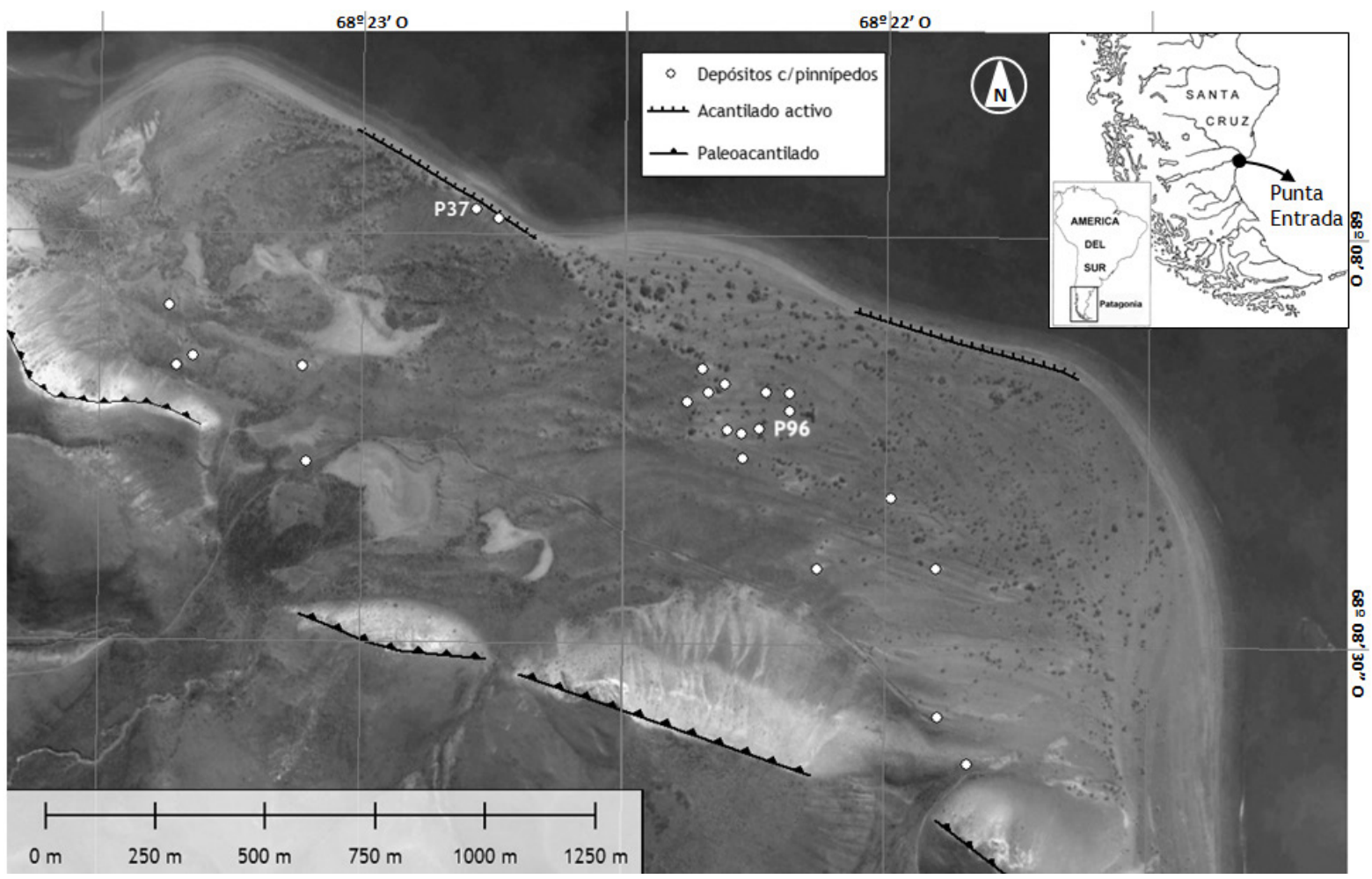

Fig. 1. Ubicación de los depósitos con restos de pinnípedos en Punta Entrada.

apostaderos de pinnípedos. Por último, se evalúa el papel de esta localidad en los circuitos de movilidad de los cazadores recolectores de la región durante los últimos 2.000 años.

\section{PUNTA ENTRADA: UBICACIÓN Y CARACTERÍSTICAS}

Punta Entrada es un territorio de acreción marino litoral, de alrededor de $2,2 \mathrm{~km}^{2}$, con un largo aproximado de $2,85 \mathrm{~km}$ y un ancho máximo de $850 \mathrm{~m}$. Situado en la margen sur de la boca del estuario del río Santa Cruz (Fig. 1), se proyecta hacia el norte a partir de un acantilado inactivo de unos $125 \mathrm{~m}$ de altura. Está constituido por una serie de playas de cordones litorales gravoarenosos con una altimetría máxima de unos 14 $\mathrm{m}$, que registran diferentes posiciones de un nivel relativo del mar sucesivamente más bajo (Ercolano 2012). La dinámica vinculada al flujo y reflujo de marea durante tormentas extraordinarias condujo a la progradación del sector desde al menos 3.550 años AP (GX-33095). Este fechado procede de un paleosuelo desarrollado sobre sedimentos eólicos que suprayacen a cordones litorales próximos al acantilado y que, a su vez, está cubierto por depósitos eólicos más jóvenes. A excepción de los cordones recientes, el resto de la punta está cubierto por médanos activos, semi-estabilizados e inactivos.

En este sector, como en todo el valle medio e inferior del río Santa Cruz, la vegetación es una estepa arbustiva baja en la que predominan la mata negra (Junellia tridens), la mata torcida (Nardophyllum obtusifollium), los molles (Schinus marchandii) y calafates (Berberis sp), además de coirones (Festuca sp., Stipa sp y Poa sp) (Oliva et al. 2001). La fauna silvestre, tanto marina como terrestre, es abundante y varias especies cumplen su ciclo reproductivo en la localidad. Entre las especies terrestres, es habitual la presencia de guanacos (Lama guanicoe), ñandúes (Rhea pennata), martinetas (Eudromia elegans) y zorros (Lycalopex culpaeus y L. griseus). Entre las marinas, se destacan los pingüinos de Magallanes (Spheniscus magellanicus), cuya área de nidificación reúne unas 48.000 parejas reproductivas (Schiavini et 
Tabla 1. Fechas-taxón de pinnípedos en depósitos arqueológicos de Punta Entrada (Santa Cruz, Argentina).

\begin{tabular}{|c|c|c|c|c|}
\hline $\begin{array}{l}\text { Depósito } \\
\text { arqueológico }\end{array}$ & $\begin{array}{c}\text { Material sobre el que se efectuó } \\
\text { el fechado }\end{array}$ & $\begin{array}{l}\text { Edad radiocarbónica } \\
\text { (años AP) }\end{array}$ & $\begin{array}{l}\text { Corrección efecto } \\
\text { reservorio }\end{array}$ & Fuente \\
\hline P 27 & $\begin{array}{c}\text { Húmero de Arctocephalus } \\
\text { australis }\end{array}$ & $\begin{array}{c}2530 \pm 50 \text { años } \\
(\text { LP 2841) }\end{array}$ & $2130 \pm 50$ & Este trabajo \\
\hline P 35 & $\begin{array}{l}\text { Radio de pinnípedo } \\
\text { indeterminado }\end{array}$ & $\begin{array}{l}1710 \pm 70 \\
(\mathrm{LP}-1791)\end{array}$ & $1310 \pm 70$ & Muñoz et al. 2009 \\
\hline P 37 & Húmero de Otaria flavescens & $\begin{array}{l}1540 \pm 70 \\
(\mathrm{LP}-1827)\end{array}$ & $1138 \pm 70$ & Muñoz et al. 2009 \\
\hline P 68 & Mandíbula de Otaria flavescens & $\begin{array}{c}1490 \pm 50 \\
(\mathrm{LP}-1848)\end{array}$ & $1090 \pm 50$ & Muñoz et al. 2009 \\
\hline P 96 & $\begin{array}{l}\text { Húmero de Arctocephalus } \\
\text { australis }\end{array}$ & $\begin{array}{l}2050 \pm 110 \\
(G X-33219)\end{array}$ & $1650 \pm 110$ & Cruz et al. 2011a \\
\hline P 96 & Húmero de Otaria flavescens & $\begin{array}{l}1330 \pm 100 \\
(G X-33090)\end{array}$ & $930 \pm 100$ & Muñoz et al. 2009 \\
\hline
\end{tabular}

al. 2005). En isla Leones, unos 7 kilómetros aguas arriba en el estuario, nidifican cormoranes imperiales (Phalacrocorax atriceps) (Frere et al. 2005). Aunque ocasionalmente se avistan lobos marinos en la desembocadura del río Santa Cruz, actualmente no se registran apostaderos en Punta Entrada. El asentamiento más cercano, de lobo común o de un pelo (Otaria flavescens), es el apostadero reproductivo de Cerro Bayo (Crespo et al. 2008; Schiavini et al 2004; Túnez et al. 2008a), que se ubica unos 24 km al sur de la desembocadura del río Santa Cruz.

\section{LOS DEPÓSITOS ARQUEOLÓGICOS}

En Punta Entrada se han registrado al menos 23 depósitos que presentan restos de pinnípedos (Fig. 1), distribuidos a lo largo de Punta Entrada y que abarcan el lapso de ocupación humana conocido para la zona. Para algunos de ellos se cuenta con fechados radiocarbónicos efectuados sobre huesos del taxón (Tabla 1). Los dos depósitos que se presentan en este trabajo se destacan por la gran cantidad y densidad de restos óseos, con buena conservación al momento de la primera observación.

P 96, el primero de estos depósitos que se intervino, se ubica en una zona de médanos a unos 550 m de la costa actual (Fig. 1), al costado de un bosquete de molles en el que hay varios nidos de pingüinos de Magallanes. Presenta muy escasas valvas de mitílidos y gran cantidad de restos de vertebrados y de artefactos líticos sobre un sustrato arenoso. Fue expuesto por la erosión eólica desencadenada principalmente por la acción excavadora y el tránsito de los pingüinos que nidifican en la localidad (Ercolano et al. 2013). Durante los trabajos de campo efectuados en noviembre de 2006 se observó que los restos de fauna mostraban poca evidencia de una exposición prolongada en la superficie, por lo que se decidió recuperarlos antes de que avanzara su deterioro. Para ello, se procedió a la recolección de los mismos en el sector de mayor concentración, a través de diez cuadrículas de $2 \mathrm{~m}$ x $1 \mathrm{~m}$. En marzo de 2007 se registraron nuevamente restos óseos expuestos en el sector de recolección, que se recuperaron utilizando las mismas unidades que en noviembre de 2006. Una recolección similar se efectuó en marzo de 2008, oportunidad en la que los materiales se encontraban sobre el sustrato con gravas característico de los cordones litorales presentes en la localidad, que consideramos como el fin del depósito. En este trabajo se presenta la totalidad de los restos recuperados en este depósito.

P 37 es otro depósito a cielo abierto, en este caso expuesto sobre un acantilado activo de aproximadamente $1,5 \mathrm{~m}$ de altura (Fig. 1). Los restos arqueológicos se encontraban contenidos en un médano y se expusieron a medida que se fue perdiendo la matriz arenosa. La erosión eólica gatillada por la acción excavadora y el tránsito de los pingüinos, unida al retroceso del acantilado fueron 
Tabla 2. P 37 y P 96: abundancia taxonómica de los conjuntos de vertebrados.

\begin{tabular}{lcc}
\hline & P 37 & P 96 \\
\hline NISP general & 2157 & 3411 \\
\%NISP pinnípedos & $92 \%$ & $75 \%$ \\
\%NISP guanacos & $0,2 \%$ & $2,5 \%$ \\
\%NISP pingüinos & $0,4 \%$ & $7 \%$ \\
\%NISP otras aves & $0,1 \%$ & $10 \%$ \\
\%NISP Peces & $0 \%$ & $0,5 \%$ \\
\% NISP Vertebrados indeterminados & $7 \%$ & $5 \%$
\end{tabular}

los procesos que generaron su exposición y pérdida parcial. Como en $\mathrm{P}$ 96, este depósito incluye escasas valvas y abundantes restos faunísticos y líticos. La recuperación se efectuó a partir de 18 cuadrículas de $2 \mathrm{~m} \times 1 \mathrm{~m}$, en tres instancias (2008, 2010 y 2011). También se efectuó un sondeo estratigráfico de un $\mathrm{m}^{2}$ que alcanzó el nivel estéril. En este trabajo se considera el material obtenido durante las dos primeras recolecciones, incluyendo variables ya discutidas previamente (Muñoz et al. 2013) y otras que se presentan aquí por primera vez.

\section{ASPECTOS METODOLÓGICOS}

Los materiales óseos se analizaron siguiendo los lineamientos comúnmente utilizados para el estudio de los conjuntos zooarqueológicos (Binford, 1981; Lyman, 1994; entre otros). Las variables que elegimos para determinar la existencia y explotación de apostaderos reproductivos son las consideradas relevantes para discutir el aprovechamiento de pinnípedos en la bibliografía especializada (Borella et al. 2014; Lyman 2003; Etnier 2007; Hildebrant \& Jones 2002; entre otros). Estas variables son la composición taxonómica de cada conjunto, la diversidad de especies de pinnípedos, las clases de edad, la representación sexual y anatómica y la presencia de modificaciones antrópicas.

La determinación taxonómica se efectuó en el nivel de especie, género o familia en todos aquellos casos en los que fue posible; en los que no lo fue, los especímenes fueron incluidos en categorías taxonómicas más amplias como aves, mamíferos, pinnípedos o vertebrados. La determinación específica de los restos de pinnípedos se efectuó según los criterios de Sanfelice \& Ferigolo (2008) para caracteres del cráneo y de Pérez García (2003) para el esqueleto post-craneal. Las asignaciones sexuales se efectuaron según caracteres de la pelvis propuestos por King (1983) y, para huesos penianos, con la colección comparativa del INCUAPA-UNICEN, a la que accedimos por gentileza de la Dra. Florencia Borella. Las clases de edad se definieron en función de tres categorías de fusión de huesos: no fusionado, semifusionado y fusionado (tal como fuera efectuado en Muñoz et al. 2013). Además, para una mayor precisión, en algunos casos se tuvo en cuenta también la propuesta de Borella y colaboradores (2011; 2013a).

Para evaluar la representación de partes esqueletarias, los elementos se agruparon en las siguientes unidades anatómicas: a) esqueleto axial: cráneo, mandíbula, vértebras, esternón y costillas; b) extremidad anterior: escápula, húmero, radio y ulna; c) extremidad posterior: pelvis, fémur, tibia y fíbula; y d) aletas: carpianos, tarsianos, metapodios y falanges.

Se relevaron las siguientes modificaciones óseas: estadios de meteorización, fracturas, daños de carnivoros, marcas de raíces, modificaciones por agua, marcas de pisoteo, modificaciones antrópicas y marcas superficiales indeterminadas. Con respecto a las modificaciones antrópicas, aquí sólo se considera su presencia/ausencia. La evaluación de todas estas modificaciones se efectuó macroscópicamente, con lupas de mano de $3 \mathrm{x}, 4 \mathrm{x}, 5 \mathrm{x}, 7 \mathrm{x}, 10 \mathrm{x}$ y $15 \mathrm{x} y$, en algunos casos, con lupa binocular de 20x aumentos, de acuerdo a los parámetros que se enumeran a continuación. Los criterios morfológicos para definir los daños de carnívoros son los determinados por Binford 
Tabla 3. P 37 y P 96: modificaciones registradas en los restos de pinnípedos. $\mathrm{S} / \mathrm{d}=$ sin datos.

\begin{tabular}{lcc}
\hline & P 37 & P 96 \\
\hline \% NISP marcas de raíces & $53 \%$ & $66 \%$ \\
\% NISP modificaciones carnívoros & $0 \%$ & $0,2 \%$ \\
\%NISP modificaciones roedores & $0 \%$ & $0,2 \%$ \\
\%NISP quemado & $\mathrm{s} / \mathrm{d}$ & $2,5 \%$ \\
\% NISP modificaciones antrópicas & $10 \%$ & $8 \%$
\end{tabular}

(1981) y para las modificaciones antrópicas se consideraron los recopilados por Muñoz (2008). Los correspondientes a daños por la acción de roedores, pisoteo y por raíces fueron tomados de la síntesis efectuada por Lyman (1994). Para evaluar la meteorización se utilizaron los estadios propuestos por Behrensmeyer (1978).

\section{RESULTADOS DEL ANÁLISIS ZOOARQUEOLÓGICO}

En ambos conjuntos predominan los restos de pinnípedos (Tabla 2), que constituyen el $75 \%$ en P 96 y el $92 \%$ en P 37. Ninguno de los otros taxones tiene una representación importante, con excepción de las aves en P 96, que incluyen a pingüinos de Magallanes (7\%) y otras aves (cormoranes, ñandú y aves voladoras indeterminadas) con un $10 \%$ del NISP. Sin embargo, es necesario aclarar que los restos

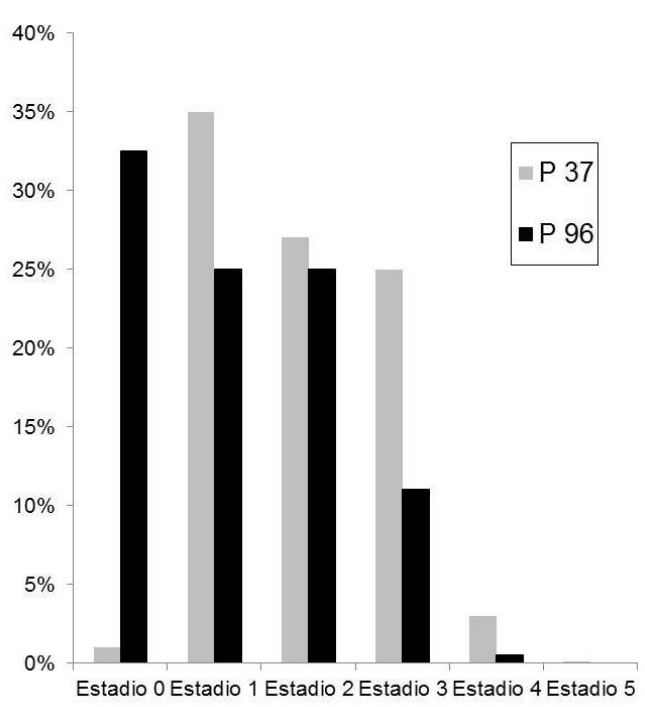

Fig. 2. Perfiles de meteorización de P 37 y P 96. de pingüinos de Magallanes de este depósito provienen de los nidos actuales ubicados a su alrededor, que se superpusieron a los materiales arqueológicos (Cruz et al. 2011a). En función de las observaciones tafonómicas que se desarrollan en la localidad (Cruz \& Muñoz 2011; Muñoz \& Cruz 2014) es posible afirmar que esto no sucede en el caso de los pinnípedos. La depositación de carcasas actuales de estos mamíferos marinos en Punta Entrada se produce en el sector más cercano a la costa atlántica, alejado de P 37 y P 96, lo que permite descartar la mezcla de restos arqueológicos y actuales de lobos marinos en ellos. Es difícil establecer si el proceso de mezcla ocurrió en algún momento del pasado y cuáles pudieron ser las condiciones para que se produjera. Sin embargo, como las corrientes cercanas a la costa tienen dirección hacia el sur (Codignotto 1997), todo posible aporte de huesos naturales debió provenir de sectores ubicados al norte de la localidad, tanto de apostaderos como individuos muertos en sus rangos de alimentación. Pero como las características y modificaciones presentes en los restos de lobos marinos de estos depósitos, que se describen a continuación, son consistentes con lo esperado para conjuntos derivados de la actividad humana, consideramos que cualquier posible aporte de huesos naturales no influyó en las características de grano grueso (sensu Binford 1981) de los conjuntos y, por consiguiente, tampoco modifica nuestras conclusiones.

El estado de conservación de los restos de pinnípedos de ambos depósitos, medido a partir de los respectivos perfiles de meteorización, es diferente (Fig. 2). En P 96 predominan los huesos no meteorizados (estadio 0), seguidos por los levemente meteorizados (estadios 1 y 2) y muy pocos especímenes en estadios 3 y 4 . En 
cambio, en P 37 predominan los huesos levemente meteorizados (estadios 1 y 2) y meteorizados (estadio 3), con escasos especímenes en estadio 0.

Las modificaciones en los restos de pinnípedos de ambos conjuntos (Tabla 3) permiten sostener que no hubo una gran destrucción por agentes como los carnívoros o los roedores. La modificación más importante, las marcas de raíces (66\% en P 96 y 53\% en P 37), tampoco es un factor de destrucción en estos casos, ya que sólo afecta la superficie de los huesos y no impide la visualización de otras modificaciones (Cruz et al. 2011a; Muñoz et al. 2013). Por otro lado, estas marcas indican que ambos conjuntos estuvieron enterrados durante al menos parte de su historia tafonómica, lo cual los protegió de los agentes atmosféricos durante ese lapso. En P 96 esto se refuerza por la recuperación de huesos en posición articular y con una coloración que indica su reciente exposición (Fig. 3) (Cruz et al. 2011a; Ercolano et al. 2013). En P 37 no se hallaron huesos en posición articular pero se registraron diferencias de coloración así como meteorización heterogénea en las distintas caras de algunos especímenes, lo que sugiere un ritmo variado de exposición de estos materiales a las condiciones subaéreas. En P 96 el 37\% del NISP de pinnípedos presenta fracturas, pero esto no afecta su identificación taxonómica ya que los especímenes corresponden a porciones que abarcan gran parte del elemento. Además, el índice de fragmentación de este depósito es muy bajo (NISP/MNE 1,5). En P 37, aunque la fragmentación tampoco es alta, es mayor que en P 96 (NISP/MNE 2,6), lo cual es acorde con el perfil de meteorización más avanzado de este conjunto. En lo que respecta a las modificaciones antrópicas, principalmente huellas de corte que afectan porcentajes bajos de especímenes, tampoco permiten suponer una gran destrucción durante el procesamiento de las carcasas (Cruz et al. 2011a; Muñoz et al. 2013, Cañete Mastrángelo et al. 2013). En síntesis, si bien existen diferencias en el tiempo de exposición, otras variables tafonómicas presentes en estos conjuntos son similares. Esto implica que aunque pudo haber factores que afectaran la representación de los taxones más pequeños o de los huesos más frágiles en P 37 debido a la meteorización, la integridad (sensu Binford 1981) del conjunto de huesos de pinnípedos de ambos depósitos no ha sido

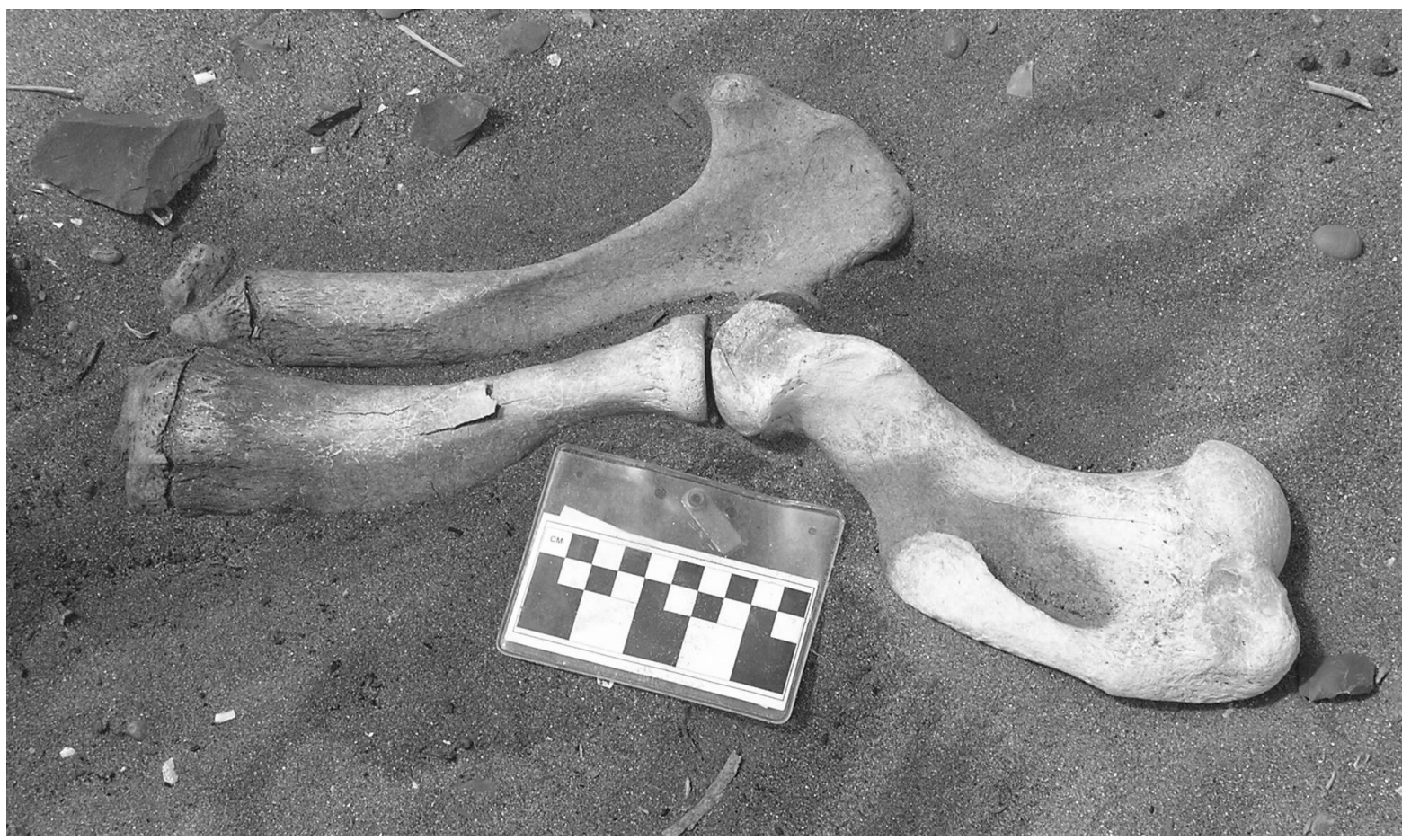

Fig. 3. Huesos articulados registrados durante la recolección de 2006 en P 96. 
Tabla 4. P 37 y P 96: abundancia taxonómica de los conjuntos de pinnípedos.

\begin{tabular}{lcc}
\hline & P 37 & P 96 \\
\hline NISP pinnípedos & 1982 & 2570 \\
\%NISP Otaria flavescens & $2 \%$ & $3 \%$ \\
\%NISP Arctocephalus australis & $10 \%$ & $0,5 \%$ \\
\%NISP pinnípedos indeterminados & $88 \%$ & $96,5 \%$
\end{tabular}

mayormente afectada.

Fue posible determinar la presencia de dos especies de pinnípedos, Otaria flavescens y Arctocephalus australis (Tabla 4). En P 96 se identificó como $O$. flavescens al $3 \%$ y como A. australis al $0,5 \%$ del NISP de pinnípedos, mientras que en $\mathrm{P} 37$ predominan los restos de A. australis, con un $10 \%$ del NISP, mientras que un $2 \%$ corresponde a $O$. flavescens. Estas diferencias no se vinculan necesariamente con la explotación de una u otra especie en cada locus y su consiguiente representación en el conjunto óseo, sino que se deben principalmente al predominio de especímenes no fusionados en P 96, lo cual dificulta la determinación específica por la abundancia de restos que no poseen rasgos diagnósticos para su identificación al nivel de especie.

Con respecto a las clases de edad, se registraron diferentes grados de fusión ósea (Tabla 5). En gran parte de los especímenes de P 37 no fue posible determinar la fusión (57\%) debido a la fragmentación, ausencia o deterioro de las zonas diagnósticas para hacerlo. Entre aquellos en los que fue posible determinarla, predominan los fusionados (25\%). En cambio, en P 96 hay un claro predominio de restos no fusionados de distintos tamaños (61\% del conjunto), mientras que los fusionados constituyen el 15\%. Según Borella y colaboradores (2013a), los restos no fusionados no corresponden sólo a cachorros o juveniles, ya que, con excepción del atlas, la fusión del esqueleto post- craneano de los otáridos comienza tardíamente y se extiende a lo largo de gran parte de la vida de los individuos. Estos investigadores señalan que, por lo tanto, puede haber animales de gran porte con sus huesos aún no fusionados.

Los datos de fusión del esqueleto postcraneano presentados por Borella y colaboradores (2013a) y Denuncio et al. (2011) permitieron mayor precisión en algunas edades. P 96 incluye especímenes correspondientes a individuos de 1-1,5 meses, determinados por huesos del basicráneo no fusionados (MNE 7). La fusión de las suturas de estos huesos, como de otras de la región neural, se produce temprano en el desarrollo (Denuncio et al. 2011) y en el caso del basicráneo puede asignarse al primer mes y medio de vida (F. Borella, comunicación personal 2014). Además, varios atlas no fusionados permitieron detectar cachorros de menos de un año. Diez fémures completamente fusionados, correspondientes a un MNI de 5 en función de lateralidad y tamaño, dan cuenta de individuos de más de 7 años. En P 37 también se recuperaron restos asignables a una gran variedad de clases de edad, en función de su tamaño y grado de fusión. Entre ellos, 5 fémures de individuos de pequeño tamaño, cuyas diáfisis son menores o iguales a $6 \mathrm{~cm}$ de largo y dos húmeros cuyas diáfisis sin fusionar son también menores a $6 \mathrm{~cm}$ de largo (MNI 2). Por otro lado, al menos un fémur de O. flavescens corresponde a un individuo adulto, probablemente macho. Algo similar ocurre con el

Tabla 5. P 37 y P 96: clases de edad de pinnípedos, determinadas según grado de fusión ósea. * Se excluyen los dientes.

\begin{tabular}{lcc}
\hline & P 37 & P 96 \\
\hline NISP pinnípedos & $1933^{*}$ & $2456^{*}$ \\
\%NISP fusionados & $25 \%$ & $15 \%$ \\
\%NISP semi-fusionados & $5 \%$ & $4 \%$ \\
\%NISP no fusionados & $13 \%$ & $61 \%$ \\
\%NISP fusión indeterminada & $57 \%$ & $20 \%$ \\
\hline
\end{tabular}


Tabla 6. P 37 y P 96: abundancia sexual de pinnípedos, determinada sobre caracteres de la pelvis (King 1983).

\begin{tabular}{lcc}
\hline & P 96 & P 37 \\
\hline NISP pelvis & 24 & 41 \\
\%NISP pelvis machos & $21 \%$ & $27 \%$ \\
\%NISP pelvis hembras & $4 \%$ & $5 \%$ \\
\%NISP pelvis indeterminadas & $75 \%$ & $68 \%$ \\
\hline
\end{tabular}

premaxilar, que indica la presencia de crías que no completaron la erupción de sus dientes caninos (MNI 2), y con el atlas (MNI 1), que al igual que en $\mathrm{P} 96$, corresponde a un individuo de menos de un año. Sin duda estos resultados serán más precisos cuando se complementen con estudios osteométricos, pero en el marco de los objetivos de este trabajo, se considera que son suficientes para determinar que existe un amplio espectro de edades representadas.

En cuanto a la diversidad sexual, en función de caracteres de la pelvis se determinaron machos y hembras en ambos depósitos (Tabla 6). En P 37 todos los casos determinables corresponden a $A$. australis, en P 96 todas las pelvis son de pinnípedos de especie indeterminada. En este último depósito también se registró un báculo o hueso peniano de A. australis (Fig. 4).

El perfil de representación de partes esqueletarias de ambos conjuntos incluye todas las unidades anatómicas (Fig. 5), pero existen diferencias entre ellos. En P 96 las extremidades tienen la representación más alta, seguidas por el esqueleto axial (especialmente mandíbulas y costillas) $y$, por último, las aletas. El perfil anatómico que presenta P 37 es coincidente con estas proporciones relativas, pero se diferencia claramente de $\mathrm{P} 96$ en que los miembros anteriores tienen una representación muy superior a los posteriores: los elementos de las extremidades anteriores (húmero MNE 55, escápula MNE 53) duplican a los correspondientes a las extremidades posteriores (Fémur MNE 23, Tibia MNE 19). Esta sobrerrepresentación de los miembros anteriores no puede explicarse a partir de la destrucción diferencial (Muñoz et al. 2013), ya que los elementos de ambas extremidades tienen un rango de resistencia comparable (Borella et al. 2008), por lo que posiblemente sea un efecto del muestreo. La representación anatómica de ambos depósitos es consistente con un escaso transporte

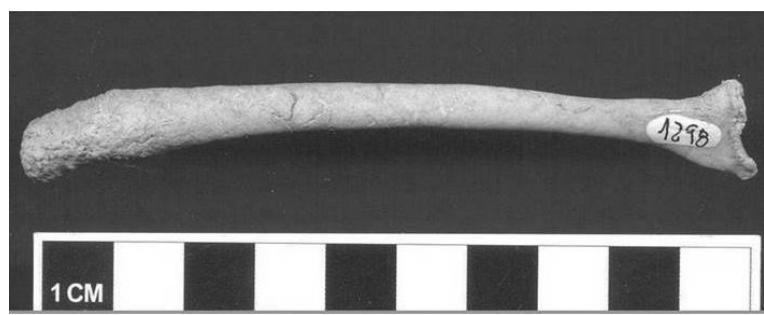

Fig. 4. Báculo o hueso peniano de A. australis recuperado en $\mathrm{P} 96$.

de individuos enteros o casi enteros.

La presencia de modificaciones antrópicas se registró en el $8 \%$ del NISP de pinnípedos de P 96 y en el 10\% de P 37 (Tabla 3). Tal como se reporta para la costa rionegrina (Borella et al. 2011), en P 96 las huellas de corte se ubican preferentemente en las costillas (especialmente en el caso de los pinnípedos de menor tamaño), que son elementos asociados a porciones de gran utilidad económica (sensu San Román 2008). P 37 , en cambio, presenta una mayor proporción de modificaciones antrópicas en las extremidades

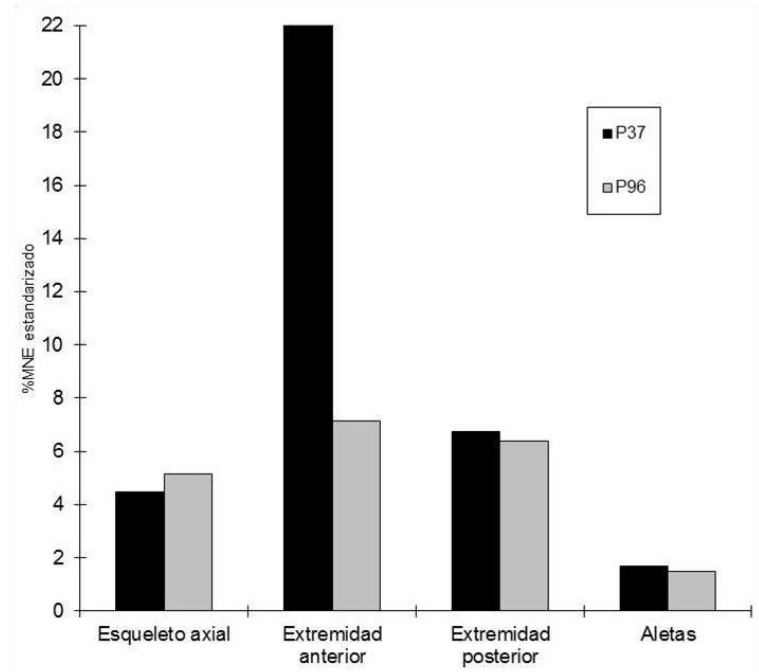

Fig. 5. Representación anatómica de P 37 y P 96. 
anteriores y las huellas más representadas en este conjunto corresponden a acciones de corte y machacado dirigidas a lograr el procesamiento completo de las presas (Cañete Mastrángelo et al. 2013).

\section{LOS PINNÍPEDOS PATAGÓNICOS EN LAS FUENTES HISTÓRICAS TEMPRANAS}

Muchos de los documentos históricos de los siglos XVI, XVII y XVIII relativos a Patagonia presentan detalladas descripciones de la región, en las que las descripciones de la fauna tuvieron un lugar destacado debido a que los animales constituían recursos vitales para abastecer a las tripulaciones durante las travesías (Astete 2006, Martinic 2012). No todas las fuentes sobre el sur de Patagonia poseen el mismo valor para obtener información sobre la fauna. Los relatos correspondientes a los momentos iniciales de exploración y reconocimiento del extremo sur del continente (siglos XVI y XVII) son menos precisos que las descripciones desarrolladas desde mediados del siglo XVIII, cuando comienzan las observaciones científicas en la región (Astete 2006).

Son varias las fuentes que advierten la gran cantidad de asentamientos de pinnípedos en el sur del continente e islas adyacentes. Por ejemplo, durante el siglo XVIII George Shelvocke (2003) relata que desde los $40^{\circ}$ a los $52^{\circ}$ de latitud sur tuvieron continuamente a la vista "bancos de focas". John Byron (Kerr 1824), a mediados de ese siglo, también se asombra por la gran cantidad de lobos marinos en el sur del continente y sugiere que su carne podría abastecer a toda la marina inglesa. Específicamente en la desembocadura del río Santa Cruz, desde el viaje de Magallanes se señala que existía una isla en la que se avistaban grandes cantidades de lobos marinos (por ejemplo, Fernández de Oviedo \& Valdés 1944; Kerr 1824; Pastells 1920). Actualmente, la isla más cercana a la desembocadura es isla Leones, por lo que suponemos que las fuentes se refieren a ella.

Un límite de la información que brindan las primeras crónicas es que no permiten discernir a cuál de las especies de pinnípedos corresponde los avistajes y si las agregaciones de animales corresponden a apostaderos reproductivos. Los primeros viajeros (siglos XVI y XVII) designan a los pinnípedos como "vacas marinas", "lobos marineros", "becerros marinos" o "focas", sin brindar elementos que permitan determinar especies. A partir del siglo XVIII, en fuentes como la del segundo viaje de James Cook entre 1772 y 1775 (Cook 1922) o del jesuita Lozano (1972), puede tenerse una primera aproximación al tema. En ellas las descripciones distinguen entre "leones de mar" (lobos comunes, O. flavescens) y "osos marinos" (lobos finos o de dos pelos, A. australis) y señalan que existen diferencias en el uso de hábitats costeros por estos mamíferos marinos. Por ejemplo, el relato del viaje de Cook incluye observaciones que indican que los leones de mar ocupaban la mayor parte de la costa, mientras que los osos de mar habitaban en las islas, señalando así las diferencias en las áreas en que se ubicaban los asentamientos de las dos especies. Aunque esta descripción es acorde con los estudios actuales (ver Distribución y características de los apostaderos de lobos marinos en Patagonia), puede ser equívoca debido a que $O$. flavescens también utiliza las islas y porque es posible que lo que registran los viajeros a partir del siglo XVIII ya esté afectado por diversos factores antrópicos, por lo que el uso de hábitat que observan los cronistas para cada especie tal vez no sea el característico de momentos previos (Cruz et al. 2014). Como ejemplos de las actividades humanas que pudieron influir en la redistribución de los asentamientos de lobos marinos se pueden mencionar el abandono de la explotación de los recursos marinos por las poblaciones nativas a partir de ese siglo (Moreno y Videla 2008, entre otros) y la explotación europeonorteamericana que caracterizó a los siglos XVIII y XIX (Crespo \& Pedraza 1991; Rodríguez \& Bastida 1998; Orquera 2002; entre otros).

\section{DISTRIBUCIÓN Y CARACTERÍSTICAS DE LOS APOSTADEROS DE LOBOS MARINOS EN PATAGONIA}

Si bien son varios los aspectos de la biología de los pinnípedos que resultan relevantes para discutir su explotación por los cazadores humanos, aquí se abordarán sólo dos de ellos: la distribución de las dos especies de interés en la costa atlántica de Patagonia y los lugares en que generalmente se ubican los apostaderos.

En el océano Atlántico, la distribución actual 
de O. flavescens se extiende desde Tierra del Fuego hasta el sur de Brasil (Crespo et al. 2012; Túnez et al. 2008a; Schiavini et al. 2005; Vaz Ferreira, 1965). En la costa patagónica hay actualmente numerosos asentamientos continentales e insulares, que son apostaderos reproductivos, de invernada o temporales. Algunos de estos apostaderos han permanecido estables a lo largo de casi 50 años mientras que otros están creciendo. Entre los 28 asentamientos registrados en la provincia de Santa Cruz, sólo dos (Cerro Bayo e Islote Lobos) tienen características de típicos apostaderos reproductivos (Schiavini et al. 2005). Los apostaderos de esta especie se ubican preferentemente en playas con escasa pendiente, de arena, gravas o rocas planas (Crespo et al 2008; Túnez et al. 2008a; Vaz Ferreira 1965). Como satélites de los criaderos, en islas o áreas externas próximas se forman anualmente lugares de machos de la especie. Túnez y colaboradores (2010) plantean que la distribución de apostaderos de $O$. flavescens se asocia a la disponibilidad de islas, por lo que su falta frente a un asentamiento impide que existan áreas alternativas para la reproducción. Con respecto a la escasez actual de colonias reproductivas de Otaria flavescens en el sur de Patagonia, estos investigadores proponen que esto se debe a la gran amplitud de mareas que afecta la línea de costa y dificulta que los lobos marinos puedan acceder al agua (Túnez et al. 2008a). En cambio, Vaz Ferreira (1965) sostiene que en la zona más austral de su distribución la especie tiene más independencia con respecto a la línea de costa y a veces se interna largas distancias en tierra. Por otro lado, la mayor amplitud de marea en la costa atlántica de Patagonia es de 13,45 m en el puerto de Río Gallegos (Servicio de Hidrografía Naval 2014) y actualmente algunos apostaderos de O. flavescens se ubican en sectores con amplitudes de marea que se aproximan a este valor.

Los lobos de dos pelos (A. australis) tienen una distribución que se superpone con la del lobo común, pero es menos continua y sus agrupaciones son mucho menos frecuentes (Crespo et al. 2008; Túnez et al. 2008b; Vaz Ferreira 1965). En la costa patagónica se encuentra el apostadero en Isla Rasa (Chubut) y otras dos concentraciones importantes en Isla Escondida (Chubut) e Isla de los Estados (Crespo et al. 2008). Los apostaderos de
A. australis se ubican en costas abruptas y rocosas de difícil acceso, en donde permanecen todo el año (Crespo et al. 2008; Túnez et al. 2008b; Vaz Ferreira 1965; entre otros). Esta especie tiene mayor dependencia de los lugares con sombra y humedad, por lo que sus asentamientos se ubican más cerca de la línea de costa, en sectores con charcos o rocas y acantilados, en los que aprovecha las cuevas y cavidades con sombra (Vaz Ferreira 1965). En la mayoría de los asentamientos actuales de A. australis en la costa patagónica también se encuentran lobos de un pelo, aunque con las mencionadas diferencias en el uso del espacio (Crespo et al. 2008).

Un último aspecto, vinculado con los asentamientos de A. australis en la costa atlántica, es que se ha propuesto que la evidencia arqueológica no indica variaciones significativas en su distribución a lo largo de los últimos 5.000 años (Túnez et al. 2013). Sin embargo, esto no necesariamente es así, ya que en los conjuntos zooarqueológicos de pinnípedos desde Río Negro hasta el estrecho de Magallanes hay gran cantidad de restos de la especie, con cronologías variables según la localidad, que muestran la importancia de su explotación por los cazadores recolectores. Por lo tanto, para establecer si hubo o no cambios en su distribución será necesario reevaluar los conjuntos zooarqueológicos de la región a la luz de los estudios sobre determinación taxonómica y etaria a partir de caracteres morfológicos, osteométricos y de fusión ósea de los Otáridos patagónicos que se han efectuando en los últimos años (Borella et al. 2013a, 2013b, 2014; Denuncio et al. 2011).

\section{DISCUSIÓN Y CONCLUSIONES}

La explotación de pinnípedos por los cazadores recolectores se ha registrado, con mayor o menor intensidad, a lo largo de toda la costa de Patagonia continental (por ejemplo, Belardi et al. 2011; Borella 2006; Borella et al. 2011; Borella et al. 2014; Caracotche et al. 2005; Cruz et al. 2011a; Gómez Otero 2006; L'Heureux \& Franco 2000; Moreno 2008; Muñoz et al. 2013; San Román 2010; entre otros). Pierotti (2013) plantea que lo inusual de la explotación de estas presas es que, generalmente, los cazadores recolectores se centran en herbivoros y no en carnivoros tope 
como los lobos marinos. Sugiere que una razón posible para la caza de estos predadores es que las cadenas tróficas en el mar son muy diferentes a las terrestres debido, entre otras cosas, a que en los ecosistemas marinos los predadores son siempre de mayor tamaño que sus presas mientras que en los ecosistemas terrestres las presas (especialmente los mamíferos) pueden ser tan o más grandes que sus predadores.

Patagonia continental se caracteriza por la baja productividad del ambiente y por la poca diversidad estructural de sus hábitats, lo que promueve una baja biomasa de vertebrados terrestres (Redford \& Eisenberg 1992). En cambio, la gran productividad de las aguas costeras del Atlántico debida a la corriente de Malvinas es fuente de alimento de grandes cardúmenes de peces y concentraciones de invertebrados, que sustentan una notable diversidad de seres vivos, especialmente aves marinas y pinnípedos (Foro para la conservación del Mar Patagónico 2008). En contextos como este son escasas las presas potenciales de tamaño mediano a grande, por lo cual para los cazadores recolectores resultan importantes los sectores del espacio donde la biomasa utilizable se presenta con mayor densidad, como es el caso de la costa (por ejemplo, Moreno 2008; Muñoz 2011; entre otros). Entonces, a pesar de que el guanaco constituyó la más importante presa terrestre para las poblaciones de cazadores continentales (Borrero 1999, 2013; entre otros), los pinnípedos se explotaron en aquellos sectores en los que estaban disponibles, ya que no sólo son presas de gran tamaño sino que, además, se presentan en agregaciones de muchos individuos (Borella 2006; entre otros).

En el caso de la desembocadura del río Santa Cruz, el análisis de P 37 y P 96 nos permite una primera aproximación a varios aspectos de la predación humana sobre estos mamíferos marinos en la localidad. En primer lugar, la gran cantidad de depósitos con restos de pinnípedos en un espacio tan reducido y el predominio de sus huesos en cada uno de ellos permite plantear que en Punta Entrada las ocupaciones humanas estuvieron fuertemente orientadas a su explotación durante los últimos 2.000 años. Además, las características de los depósitos analizados (predominio de pinnípedos, representación de las dos especies, presencia de ambos sexos y de individuos maduros e inmaduros, restos de individuos de 1-1,5 meses y presencia de modificaciones antrópicas) hacen posible proponer que esta explotación se centraba en un apostadero reproductivo. La representación anatómica registrada muestra que muchos de los individuos fueron transportados enteros o casi enteros (por ejemplo, en el caso de los de menor edad/tamaño en P 96), por lo que consideramos que este apostadero no se encontraba alejado. Tal como plantean Borella y colaboradores (2014), los cazadores de Patagonia continental no contaban con tecnología de embarcación, por lo que la caza de pinnípedos se realizaba en tierra y las carcasas no se transportaban largas distancias.

De acuerdo con las propiedades que generalmente presentan los sectores en que se ubican las áreas de cría, este apostadero reproductivo pudo haber estado emplazado sobre la costa atlántica, donde el paleoacantilado y la playa presentan actualmente características apropiadas. Además, si se tiene en cuenta la progresiva acreción de los cordones litorales de Punta Entrada desde ca. 3.550 AP, es posible sostener que la línea de costa durante parte del lapso de interés debió estar mucho más cerca del acantilado que en la actualidad. Por lo tanto, es probable que su paisaje también haya tenido una fisonomía como la que se postula para la instalación de asentamientos de estos mamíferos marinos. De hecho, el apostadero reproductivo actual de Cerro Bayo se ubica en un ambiente similar, es decir una estrecha playa de grava vinculada a un acantilado activo sobre la costa atlántica, a unos $24 \mathrm{~km}$ al sur de Punta Entrada, en un sector con amplitud máxima de marea de ca. $12 \mathrm{~m}$. Esta cercanía entre la ubicación del asentamiento actual y la propuesta para el pasado sería consistente con el patrón de formación de colonias, que determina que, en muchos casos, las nuevas se formen cerca de las más establecidas (Crespo et al. 2012; Túnez et al. 2008a). Con respecto a la isla en la desembocadura del río Santa Cruz mencionada en las fuentes históricas, por el momento no es posible establecer si alli se emplazaba un apostadero reproductivo o de otro tipo, y a que especie podría corresponder. Es necesario aclarar que la isla Leones no está formada por roca dura sino por material sedimentario, por lo que no constituye el 
típico hábitat de A. australis.

Según la información biológica, el sector sobre la costa atlántica sería apropiado para que se asentase una colonia de cría de O. flavescens, ya que los hábitats utilizados actualmente por A. australis son diferentes. Sin embargo, si se acepta que es posible que previamente los lobos finos utilizaran cualquier tipo de costa para sus asentamientos y que lo que se observa actualmente es un reflejo de la historia de la especie posterior al siglo XVIII, entonces podría haber sido utilizado por cualquiera de las dos especies. La presencia de $A$. australis y $O$. flavescens en los depósitos de Punta Entrada apoya la idea de que utilizaban hábitats similares.

Los apostaderos pudieron incluir individuos de ambas especies (Cruz et al. 2011a). También es posible que estas especies ocuparan simultáneamente sectores diferentes en Punta Entrada, o que no estuvieran presentes durante el mismo rango temporal (Muñoz et al. 2013). Los fechados disponibles hasta el momento para A. australis (Tabla 1) permiten establecer que se encontraba presente entre ca. 2.100 y 1.600 AP. En cambio, la cronología de O. flavescens sitúa a la especie en la localidad entre ca. 1.100 y 900 AP. Estos fechados son insuficientes para discutir diferencias cronológicas en el uso de Punta Entrada por una u otra especie, por lo que más fechas-taxón están en curso.

Con respecto al lugar de esta localidad en la subsistencia y movilidad humana durante los últimos 2.000 años, la importante explotación de los pinnípedos evidenciada en los dos conjuntos analizados no es consistente con la información isotópica de restos humanos que corresponden al lapso de ocupación considerado (Cruz et al. 2011a). Sobre un total de 9 individuos recuperados en la cuenca inferior del río Santa Cruz y P. N. Monte León, se pudo obtener información isotópica para cinco de ellos (Guichón et al. 2012; Suby et al. 2009), ya que los restantes no presentaban condiciones de preservación que permitieran fechados o análisis isotópicos. La dieta determinada muestra el consumo predominante de recursos terrestres, con una ingesta baja de alimentos marinos. Esto es interesante, debido a que tres de los individuos fueron recuperados en asociación directa a concheros en los que predominan los restos de fauna marina. Esta discordancia entre la información isotópica humana y la información zooarqueológica también ha sido registrada al norte (Moreno et al. 2011) y al sur (Borrero \& Barberena 2006; Borrero et al. 2009) de Punta Entrada y permite plantear que los pinnípedos u otros recursos marinos no constituían el ítem principal en la subsistencia de los cazadores recolectores.

En Punta Entrada se han registrado otros materiales, como un artefacto en asta de huemul (Hippocamelus bisulcus) (Cruz et al. 2010) y obsidianas procedentes de Pampa del Asador, cordón Baguales y seno de Otway (Cruz et al. 2011b), que señalan que la circulación de bienes abarcaba territorios amplios que, además de este y otros sectores costeros cercanos, seguramente incluían hábitats continentales hasta el bosque andino al pié de la cordillera de los Andes. Por otro lado, la evidencia permite proponer que la presencia humana en la costa no era continua y que no se relacionaba con una estación específica. Por ejemplo, los restos de cachorros de lobo marino de menos de dos meses en el conjunto de P 96 permiten establecer la presencia humana durante el verano austral, mientras que el análisis de anillos de crecimiento de caninos de pinnípedos de P 132 (Pretto 2013), también en Punta Entrada, mostró que las ocupaciones no respondían a una estación en particular sino a distintos momentos del año. Es decir, estos resultados no se adecuan a la idea de uso estacional de la costa patagónica que se sostuvo por muchos años. Consideramos además que es muy posible que la explotación de estos apostaderos ocurriera en intervalos variables de tiempo (incluso separados por varios años), que se reiteraron a lo largo del lapso de ocupación humana de la localidad, que fue integrada a circuitos de movilidad que abarcaban territorios amplios y que no necesariamente permanecieron estables en el largo plazo.

Lanata y Winograd (1988) plantearon que si bien los cazadores nativos de Tierra del Fuego no diezmaron las poblaciones de lobos marinos, influyeron sobre la forma en que ocupaban el paisaje, principalmente los lugares en los que instalaban sus apostaderos. No creemos que esto pueda sostenerse para el caso de Punta Entrada, donde la explotación, aunque recurrente, 
seguramente no tuvo la continuidad que caracterizó a los casos fueguinos. Por otro lado, recientemente se determinó que la explotación más intensa de pinnípedos por los cazadores recolectores de la costa atlántica de Norpatagonia y de canal Beagle se inició en momentos de alta productividad primaria oceánica y declinó cuando la misma disminuyó (Saporiti et al. 2014). Estos autores concluyen que lo que controla a las poblaciones de pinnípedos en Patagonia es, por lo tanto, la productividad primaria y no la actividad de los cazadores humanos del Holoceno, lo cual es otro argumento para sostener que el impacto de las poblaciones humanas sobre los pinnípedos de Punta Entrada no pudo ser importante.

\section{CONSIDERACIONES FINALES}

El análisis zooarqueológico de P 37 y P 96 permite un primer abordaje del tema de la existencia y explotación de apostaderos reproductivos de pinnípedos en la costa al sur del río Santa Cruz. En conjunto con lo aportado por las fuentes históricas y la información biológica actual acerca de los apostaderos reproductivos es posible pensar escenarios tentativos que tienen en cuenta los diversos cambios que pudieron combinarse a lo largo de la historia de estas especies y sus interacciones con las poblaciones humanas. El más importante de estos cambios es la existencia de uno o más apostaderos de pinnípedos en la localidad a lo largo de los últimos 2.000 años, lo cual posibilitó que las poblaciones de cazadores recolectores los explotaran recurrentemente, aunque su subsistencia se basaba preferentemente en el guanaco. Desde el punto de vista de la historia natural de los pinnípedos, resta todavía establecer si efectivamente las dos especies (o sólo una) utilizaban Punta Entrada como área de cría y si hubo o no diferencias cronológicas en la presencia de cada una de ellas.

Comprender la dinámica de las interacciones entre poblaciones humanas y de pinnípedos en la costa del sur de Patagonia continental requiere la utilización de múltiples líneas de evidencia y la resolución de casos particulares como el que aquí presentamos. En el futuro, esto permitirá contar con bases firmes para un abordaje en escala regional, que es el adecuado para responder preguntas acerca de las características de la predación humana sobre estas poblaciones de pinnípedos durante el Holoceno.

\section{AGRADECIMIENTOS}

A la Dra. Florencia Borella, quien gentilmente nos asesoró en la determinación específica y de clases de edad de los materiales de P 96. A la Municipalidad de Puerto Santa Cruz, por su apoyo en la logística de los trabajos de campo en Punta Entrada. A Don Víctor López, de Estancia Monte Entrance. A Soledad Caracotche y los miembros del equipo con quienes efectuamos las tareas de campo y de laboratorio. Una versión preliminar de este trabajo fue presentada como póster durante el II ELAZ (mayo-junio de 2012, Santiago de Chile), agradecemos los comentarios recibidos. Este es un resultado de los proyectos UNPA 29/A302 y PIP/ CONICET 112-201201-00359.

\section{BIBLIOGRAFÍA}

Astete, F. (2006). Las expediciones a la Patagonia Austral durante los siglos XVI-XVII-XVIII. Espacios, 30, 9-14.

Behrensmeyer, A. K. (1978). Taphonomic and Ecological Information from Bone Weathering. Paleobiology, 4, 150-162.

Belardi, J. B., Carballo Marina, F. \& L'heureux, G. L. (2011). Nuevos resultados arqueológicos en Cabo Vírgenes (Santa Cruz, Argentina): el sitio Cabo Vírgenes 20. Magallania, 39(2), 279-292.

Binford, L. R. (1981). Bones. Ancient men and modern myths. New York, NY: Academic Press,

Borella, F. (2006). ¿Dónde están los lobos en la costa atlántica de Norpatagonia? Explorando vías para resolver el registro arqueofaunístico. Werken, 6, 97-114.

Borella, F. (2010). Revisando la interpretación de los restos de lobos marinos en el registro arqueológico. El caso de Cabo Vírgenes (Patagonia Meridional). En L. A. Borrero \& Charlin, J. (Eds.), Arqueología de Pali Aike y Cabo Vírgenes, (pp. 123-135). Buenos Aires, BA: Editorial Dunken.

Borella, F., Scartarscini, F. L. \& Marani, H. (2011). Explorando la subsistencia humana a partir de la evidencia faunística en la costa rionegrina. En Borella y M. Cardillo (Comps.) Arqueología de pescadores y marisqueadores en Nordpatagonia. Descifrando un registro de más de 6.000 años, (pp. 88-110). Buenos Aires, BA: Editorial 
Dunken.

Borella, F., Grandi, F. Vales, D. G., R. N. Goodall \& Crespo, E. A. (2013a). Esquema preliminar de fusión epifisaria en huesos de lobos marinos (Arctocephalus australis y Otaria flavescens), su contribución en los análisis zooarqueológicos. En A. F. Zangrando; R. Barberena; A. Gil; G. Neme; M. Giardina; L. Luna; C. Otaola; S. Paulides; L. Salgán y A. Tívoli (Comps.), Tendencias teórico-metodológicas y casos de estudio en la arqueología de la Patagonia (pp. 39-51). San Rafael, Mendoza: Museo de Historia Natural.

Borella, F., Gutierrez, M. A., Fodere, H. R. \& Merlo, J. F. (2008). Estudio de densidad mineral ósea para dos especies de otáridos frecuentes en el registro arqueofaunístico patagónico. En F. Morello, M. Martinic, A. Prieto y G, Bahamonde (Eds.) Arqueología de Fuego-Patagonia. Levantando piedras, desenterrando huesos... y develando arcanos (pp. 421-426). Punta Arenas, PA: Ediciones CEQUA.

Borella, F., L'heureux, L. \& Grandi, M. F. (2014). Osteometric analysis of South American Sea Lions (Otaria flavescens) pups from Patagonia. An assessment of their use as indicators for seasonality in archaeological sites. International Journal of Osteoarchaeology DOI: 10.1002/oa.2392

Borella, F. Vales, D. G., Grandi, M. F., García, N. A. \& Crespo, E. A. (2013b). Rasgos morfológicos diagnósticos en huesos del postcráneo para la identificación de Otáridos en el registro zooarqueológico. Libro de Resúmenes III Congreso Nacional de Arqueología Argentina, (pp. 34), Instituto Interdisciplinario de Tilcara, Universidad de Buenos Aires.

Borrero, L. A. (1999). The Prehistoric Exploration and Colonization of Fuego-Patagonia. Journal of World Prehistory, 13(3), 321-355.

Borrero, L. A. (2013). Estrategias de caza en Fuego-Patagonia. Comechingonia. Revista de Arqueología, 17(1), 1126.

Borrero, L. A. \& Barberena, R. (2006). Hunter-Gatherer Home Ranges and Marine Resources. An Archaeological Case from Southern Patagonia. Current Anthropology, 47, 855-867.

Borrero, L. A. Barberena, R., Franco, N. V., Charlin, J. \& Tykot, R. H. (2009). Isotopes and Rocks: Geographical Organisation of Southern Patagonian Hunter-Gatherers. International Journal of Osteoarchaeology, 19, 309327.

Cañete Mastrángelo, D. S., Muñoz, A. S. \& Pretto, A. (2013). El procesamiento de pinnípedos en $\mathrm{P} 37$, desembocadura del río Santa Cruz, Patagonia Meridional. En J. R. Bárcena y S. E. Martín (Eds.), Arqueología Argentina, en el Bicentenario de la Asamblea General Constituyente del año 1813 (pp. 566-567). La Rioja: Universidad Nacional de La Rioja.

Caracotche, M. S., Cruz, I., Espinosa, S., Carballo, F. \& Belardi, J. B. (2005). Rescate arqueológico en el Parque Nacional Monte León (Santa Cruz, Argentina). Magallania, 33(2), 143-163.

Cook, J. (1922). Viaje hacia el Polo Sur y alrededor del mundo. Madrid: Editorial Calpe.

Codignotto, J. (1997). Geomorfología y dinámica costera. El mar Argentino y sus recursos pesqueros, 1, 89-105.

Crespo, E. \& Pedraza, S. (1991). Estado actual y tendencia de la población de lobos marinos de un pelo (Otaria flavescens) en el litoral patagónico. Ecología austral, 1, 87-95.

Crespo, E., García, N. Dans, S. \& Pedraza, S. (2008). Arctocephalus australis. Otaria flavescens. Atlas de sensibilidad ambiental de la costa y el mar Argentino. http://atlas.ambiente.gov.ar

Crespo, E., Oliva, D., Dans, S. \& Sepúlveda, M. (eds.) 2012. Estado de situación del lobo marino común en su área de distribución. Universidad de Valparaíso Editorial.

Cruz, I., Caracotche, M. S., Stern, C., Muñoz, A. S., Suby, J., Lobbia, P., Ercolano, B. \& Cañete Mastrángelo, D. (2011b). Obsidianas y otros indicadores de movilidad en Punta Entrada y P. N. Monte León (Santa Cruz, Argentina). Libro de Resúmenes VIII Jornadas de Arqueología de la Patagonia (pp. 28-29). Malargüe, Mendoza.

Cruz, I., Lemaire, C. R., Nauto, G. \& Astete, F. (2014). Historia natural de pingüinos y lobos marinos en Patagonia. Desde la Patagonia. Difundiendo saberes, 11(17), 2-9.

Cruz, I. \& Muñoz, A. S. (2011). Meteorización de restos óseos de guanaco y lobos marinos: cambio $y$ estabilidad en carcasas y conjuntos actuales en Punta Entrada y Monte León (costa atlántica de Patagonia). Libro de Resúmenes del II Congreso Nacional de Zooarqueología Argentina (pp. 28), Buenos Aires, BA: FACSO, Universidad Nacional del Centro de la Provincia de Buenos Aires, Olavarría.

Cruz, I., Muñoz, A. S. \& Caracotche, M. S. (2010). Un artefacto en asta de huemul (Hippocamelus bisulcus) en depósitos arqueológicos costeros. Implicaciones para la movilidad humana y la distribución de la especie. Magallania, 38(1), 289-296.

Cruz, I. Muñoz, A. S. \& Lobbia, P. A. (2011a.) La explotación de 
recursos marinos en la costa de Patagonia continental: los restos de vertebrados en depósitos de Punta Entrada y Monte León (Santa Cruz, Argentina), Revista de estudios marítimos y sociales, 4, 31-41.

Denuncio, P., Mandiola, M. A., Bastida, R. \& Rodríguez, D. (2011). Patrón de cierre sutural y sus variaciones en el cráneo del lobo marino de dos pelos Arctocephalus australis (Zimmermann, 1783). Natura Neotropicalis, 42, 5-20.

Ercolano, B. (2012). Esquema evolutivo de Punta Entrada, desembocadura del río Santa Cruz. Resúmenes de las VIII Jornadas Nacionales de Ciencias del Mar, XVI Coloquio de Oceanografía (pp. 106), Comodoro Rivadavia.

Ercolano, B., Cruz, I. \& Marderwald, G. (2013). Registro arqueológico y procesos de formación en Punta Entrada (Santa Cruz, Patagonia Argentina). En R. Bárcena y S. E. Martín (Eds.), Arqueología Argentina en el Bicentenario de la Asamblea General Constituyente del año 1813, (pp. 527), La Rioja: Universidad Nacional de la Rioja.

Etnier, M. A. (2007). Defining and identifying sustainable harvests of resources: Archaeological examples of pinniped harvests in the eastern North Pacific. Journal for Nature Conservation, 15, 196-207.

Fernández De Oviedo \& Valdés, G. (1944). Historia general y natural de las Indias. Editorial Guarania, Asunción del Paraguay.

Foro para la Conservación del Mar Patagónico (2008). Síntesis del estado de conservación del Mar Patagónico y áreas de influencia. Puerto Madryn, Argentina.

Frazier, J. (2007). Sustainable use of wildlife: The view from archaeozoology. Journal for Nature Conservation 15:163-173.

Frere, E., Quintana, F. \& Gandini, P. (2005). Cormoranes de la costa patagónica: estado poblacional, ecología y conservación. El Hornero, 20(1), 35-52.

Gómez Otero, J. (2006). Dieta, uso del espacio y evolución en poblaciones cazadoras-recolectoras de la costa centroseptentrional de Patagonia durante el Holoceno medio y tardío. Tesis Doctoral, Facultad de Filosofía y Letras, Universidad de Buenos Aires.

Guichón R. A., Suby, J. A. \& Garcia Laborde, P. (2012). Cerro Observación: Parque Nacional Monte León, Santa Cruz. Informe para la Administración de Parques Nacionales.

Hildebrandt, W. R. \& Jones, T. L. (1992). Evolution of marine mammal hunting: A view from the California and Oregon coasts. Journal of Anthropological Archaeology, 11, 360-401.
Kerr, R. (1824). General History and collection of voyages and travels, arranged in systematic order: forming a complete history of the origin and progress of navigation, discovery, and commerce, by sea and land, from the earliest ages to the present time. Volume XII, Part III. William Blackwood, Londres.

King, J. E. (1983). Seals of the world. British Museum (Natural History). Cornell University Press, New York.

Lanata, J. L. \& Winograd, A. (1988). Gritos y susurros: aborígenes y lobos marinos en el litoral de la Tierra del Fuego. En Arqueología de las Américas. 45 Congreso Internacional de Americanistas. Fondo de Promoción de la Cultura pp. (227-246), Bogotá.

Legoupil, D. (2003). Cazadores-recolectores de Ponsonby (Patagonia Austral) y su paleoambiente desde VI al III milenio AC. Magallania Tirada Especial (Documentos), 31.

L'heureux, G. L. \& Franco, N. V. (2002) Ocupaciones humanas en el área de Cabo Vírgenes (Pcia. de Santa Cruz, Argentina): el sitio Cabo Vírgenes 6. Anales del Instituto de la Patagonia, 30, 183-201

Lozano, P. (1972) (1836). Diario de un viaje a la costa de la mar magallánica en 1745 desde Buenos Aires hasta el estrecho de Magallanes. En P. de Angelis (Comp.), Colección de Obras y Documentos relativos a la Historia Antigua y Moderna de las Provincias del Río de la Plata, Tomo Octavo, Volumen II. Buenos Aires, BA: Editorial Plus Ultra.

Lyman, R. L. (1994). Vertebrate Taphonomy. Cambridge University Press, Cambridge.

Lyman, R. L. (2003). Pinniped behavior, foraging theory, and the depression of metapopulations and nondepression of a local population on the southern Northwest Coast of North America. Journal of Anthropological Archaeology, 22, 376-388.

Lyman, R. L. (2011). A warrant for applied palaeozoology. Biological Reviews, 87, 513-525.

Lyman, R. L. \& Cannon, K. P. (2004). Zooarchaeology and Conservation Biology. The University of Utah Press. Salt Lake City.

Martinic B., M. (2012). Los holandeses en la isla de los Pingüinos. Magallania, 40(2), 7-22.

Moreno, E. (2008). Arqueología y etnohistoria de la Costa Patagónica Central en el Holoceno Tardío. Fondo Editorial de la Provincia del Chubut, Rawson, Argentina.

Moreno, E. \& Videla, B. (2008). Rastreando ausencias: la hipótesis del abandono del uso de los recursos marinos en el momento ecuestre en la Patagonia continental. Magallania, 36(2), 91-104. 
Moreno, E., Zangrando, A. F. J., Tessone, A., Castro, A. \& Panarello, H. (2011). Isótopos estables, fauna y tecnología en el estudio de los cazadores-recolectores de la costa norte de Santa Cruz. Magallania, 39(1), 265-276.

Muñoz, A. S. (2008). El procesamiento de los camélidos fueguinos en el pasado. Aspectos metodológicos y resultados alcanzados para el sector atlántico de Tierra del Fuego. En A. Acosta, D. Loponte \& L. Mucciolo (Comps.), Temas de arqueología. Estudios Zooarqueológicos y Tafonómicos (I), (pp. 77-97), Buenos Aires, BA: Instituto Nacional de Antropología y Pensamiento Latinoamericano.

Muñoz, A. S. (2011). Human-pinniped relationships in Southern Patagonia. In N. F. Bicho, J. A. Haws, \& L. G. Davis (Eds.), Current issues and future research agenda. Trekking the shore: changing coastlines and the antiquity of coastal settlement (pp. 305-332), Springer.

Muñoz, A. S., Caracotche, M. S. \& Cruz, I. (2009). Cronología de la costa al sur del río Santa Cruz: nuevas dataciones en Punta Entrada y Parque Nacional Monte León (Provincia de Santa Cruz, Argentina). Magallania, 37(1), 39-43.

Muñoz, A. S. \& Cruz, I. (2014). Investigaciones tafonómicas naturalistas en Punta Entrada (Santa Cruz, Patagonia Argentina): estado actual y perspectivas. Revista Chilena de Antropología (en prensa).

Muñoz, A. S., Cruz, I., Lemaire, C. R. \& Pretto, A. (2013). Los restos arqueológicos de pinnípedos de la desembocadura del río Santa Cruz (Punta Entrada, costa atlántica de Patagonia) en perspectiva regional. En A. F. Zangrando; R. Barberena; A. Gil; G. Neme; M. Giardina; L. Luna; C. Otaola; S. Paulides; L. Salgán y A. Tívoli (Comps), Tendencias teórico-metodológicas y casos de estudio en la arqueología de la Patagonia (pp. 459-467). San Rafael, Mendoza: Museo de Historia Natural.

Oliva, G., González, L., Rial, P. \& Livraghi, E. (2001). El ambiente en la Patagonia Austral. En P. Borelli y G. Oliva (eds.) Ganadería ovina sustentable en la Patagonia Austral (pp. 17-80), Instituto Nacional de Tecnología Agropecuaria, EEA Santa Cruz - Convenio INTA-CAP-UNPA.

Orquera, L. A. (2002). The late-nineteenth-century crisis in the survival of the Magellan-Fueguian littoral natives. In C. Briones y J. L. Lanata (Eds.), Archaeological and Anthropological Perspectives on the Native Peoples of Pampa, Patagonia and Tierra del Fuego to the Nineeteenth Century (pp. 145-158). Bergin y Garvey,
Westport.

Pastells, P. (1920). El descubrimiento del Estrecho de Magallanes. $1^{\text {a }}$ parte. Madrid: Editorial Hispano Americana.

Pérez García, M. I. (2003). Osteología comparada del esqueleto postcraneano de dos géneros de Otariidae de Uruguay. Boletín Sociedad Zoológica de Uruguay, 14, 1-16.

Pierotti, R. (2013). Review of "Human Impacts on Seals, Sea Lions, and Sea Otters: Integrating Archaeology and Ecology of the Northeast Pacific". Ethnobiology, 4, 32-36.

Pretto, A. (2013). Determinación de edad y estacionalidad de muerte en dientes caninos de Otaria flavescens y Arctocephalus australis en Punta Entrada y Parque Nacional Monte León (Santa Cruz, Argentina). Póster presentado en Tercer Congreso Nacional de Zooarqueología Argentina, Instituto Interdisciplinario Tilcara, Universidad de Buenos Aires, 9 al 13 de septiembre de 2013, Tilcara, Jujuy, Argentina.

Redford, K. H. \& Eisenberg, J. F. (1992). Mammals of the Neotropics. The Southern Cone. Vol. 2. Chile, Argentina, Uruguay, Paraguay. Chicago, $\mathrm{CH}$ : The University of Chicago Press, .

Rodríguez, D. \& Bastida, R. (1998). Four hundred years in the history of pinniped colonies around Mar del Plata, Argentina. Aquatic Conservation: Marine and Freshwate. Ecosystems, 8, 721-735.

Sanfelice, D. \& Ferigolo, J. (2008). Estudo comparativo entre os sincrânios de Otaria byronia e Arctocephalus australis (Pinnipedia, Otariidae). Iheringia. Série Zoologica, 98(1), 5-16.

San Román, M. (2008). Anatomía económica de Otaria flavescens (Shaw, 1800). En P. López, I. Cartajena, C. García y F. Mena Larraín (Eds.) Zooarqueología $y$ tafonomía en el confín del mundo, Monografías Arqueológicas $N^{\circ} 1$ (pp. 169-179). Santiago de Chile> Facultad de Estudios del Patrimonio Cultural, Universidad Internacional SEK,

San Román, M. (2010). La explotación de recursos faunísticos en el sitio Punta Santa Ana 1: estrategias de subsistencia de grupos de cazadores marinos tempranos de Patagonia Meridional. Magallania, 38(1), 183-198.

Saporiti, F., Bala, L. O., Gómez Otero, J., Crespo, E. A., Piana, E. L., Aguilar, A. \& Cardona, L. (2014). Paleoindian pinniped exploitation in South America was driven by oceanic productivity. Quaternary International. http://dx.doi.org/10.1016/j.quaint.2014.05.015

Schiavini, A., Yorio, P., Gandini, P., Raya Rey, A. \& Boersma, P. D. (2005). Los pingüinos en las costas argentinas: 
estado poblacional y conservación. El Hornero, 20(1), 5-23.

Schiavini, A. C. M., Crespo, E. A. \& Szapkievich, V. (2004). Status of the population of South American sea lion (Otaria flavescens Shaw, 1800) in Southern Argentina. Mammalian Biology, 69(2), 108-118.

Servicio de Hidrografía Naval (2014). http://www.hidro.gov. ar/oceanografia/Tmareas/Form_Tmareas.asp

Shelvocke, G. (2003). Un viaje alrededor del mundo. Por la ruta del Gran Mar del Sur. Buenos Aires, BA: Eudeba.

Suby, J., Guichón, R. A. \& Zangrando, A. F. J. (2009). E registro biológico humano de la costa meridional de Santa Cruz. Revista Argentina de Antropología Biológica, 11(1), 109-124.

Túnez, J. I., Capozzo, H. L. \& Cassini, M. H. (2008a). Natural and anthropogenic factors associated with the distribution of South American sea lion along the Atlantic coast. Hydrobiologia, 598, 191-202.

Túnez, J. I., Cappozzo, H. L. \& Cassini, M. H. (2008b). Regional factors associated with the distribution of South American fur seals along the Atlantic coast of South America. ICES Journal of Marine Science Advance doi:10.1093/icesjms/fsn168

Túnez, J. I., Cappozzo, H. L., Pavés, H., Albareda, D. A. \& Cassini, M. H. (2013). The role of Pleistocene glaciations in shaping the genetic structure of South American fur seals (Arctocephalus australis). New Zealand Journal of Marine and Freshwater http://dx.doi.org/10.1080/0 0288330.2012 .753463

Vaz Ferreira, R. (1965). Ecología terrestre y marina de pinnípedos en el Atlántico Sudoccidental. Anais Academia Brasileira de Ciencias, 37, 179-191. 